\title{
Effect of pulmonary hypertension on exercise tolerance in patients with COPD: a prognostic systematic review and meta-analysis
}

\author{
Rodrigo Torres-Castro $\mathbb{( D D}^{1,2}$, Elena Gimeno-Santos $\mathbb{1}^{1,3}$, Jordi Vilaró $\mathbb{1}^{4}$, Marta Roqué-Figuls $\mathbb{\circledR}^{5,6}$, \\ Jorge Moisés $\mathbb{1}^{1,7}$, Luis Vasconcello-Castillo ${ }^{2}$, Tanya Orizaga ${ }^{1}$, Joan Albert Barberà $\mathbb{1}^{1,7,8}$ and \\ Isabel Blanco (1) $1,7,8$
}

\begin{abstract}
${ }^{1}$ Dept of Pulmonary Medicine, Hospital Clínic-Institut d'Investigacions Biomèdiques August Pi i Sunyer (IDIBAPS), University of Barcelona, Barcelona, Spain. ${ }^{2}$ Dept of Physical Therapy, Faculty of Medicine, University of Chile, Santiago, Chile. ${ }^{3}$ Barcelona Institute for Global Health (ISGlobal), Barcelona, Spain. ${ }^{4}$ Blanquerna School of Health Sciences, Global Research on Wellbeing (GRoW), Universitat Ramon Llull, Barcelona, Spain. ${ }^{5}$ Iberoamerican Cochrane Centre - Biomedical Research Institute Sant Pau (IIB Sant Pau), Barcelona, Spain. ${ }^{6}$ CIBER Epidemiología y Salud Pública (CIBERESP), Madrid, Spain. ${ }^{7}$ Biomedical Research Networking Center on Respiratory Diseases (CIBERES), Madrid, Spain. ${ }^{8}$ Contributed equally as senior authors.
\end{abstract}

Corresponding author: Isabel Blanco (iblanco2@clinic.cat)

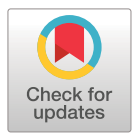

Copyright (C) The authors 2021

This version is distributed under the terms of the Creative Commons Attribution Non-Commercial Licence 4.0. For commercial reproduction rights and permissions contact permissions@ersnet.org

Received: 3 Oct 2020 Accepted: 17 Dec 2020

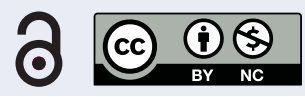

Shareable abstract (@ERSpublications)

The $V^{\prime}{ }_{O_{2 p a k}}$, Wmax and $\mathrm{O}_{2}$ pulse values were significantly lower in patients with COPD-PH than in patients with COPD-nonPH, particularly in nontransplant candidates https://bit.ly/3s5dtJ9

Cite this article as: Torres-Castro R, Gimeno-Santos E, Vilaró J, et al. Effect of pulmonary hypertension on exercise tolerance in patients with COPD: a prognostic systematic review and meta-analysis. Eur Respir Rev 2021; 30: 200321 [DOI: 10.1183/16000617.0321-2020].

\section{Abstract}

Background Pulmonary hypertension (PH) is a frequent complication in patients with COPD. Objective To determine if, in patients with COPD, the presence of $\mathrm{PH}$ decreases exercise tolerance. Methods We included studies that analysed exercise tolerance using a cardiopulmonary exercise test (CPET) in patients with COPD with PH (COPD-PH) and without PH (COPD-nonPH). Two independent reviewers analysed the studies, extracted the data and assessed the quality of the evidence.

Results Of the 4915 articles initially identified, seven reported 257 patients with COPD-PH and 404 patients with COPD-nonPH. The COPD-PH group showed differences in peak oxygen consumption $\left(V_{\mathrm{O}_{2 \text { peak }}}^{\prime}\right),-3.09 \mathrm{~mL} \cdot \mathrm{kg}^{-1} \cdot \mathrm{min}^{-1}(95 \% \mathrm{CI}-4.74$ to $-1.43, \mathrm{p}=0.0003)$; maximum workload $\left(\mathrm{W}_{\text {max }}\right)$, $-20.5 \mathrm{~W}$ (95\% CI -34.4 to $-6.5, \mathrm{p}=0.004)$; and oxygen pulse $\left(\mathrm{O}_{2}\right.$ pulse), $-1.24 \mathrm{~mL} \cdot$ beat $^{-1}$ (95\% CI -2.40 to $-0.09, \mathrm{p}=0.03)$, in comparison to the group with COPD-nonPH. If we excluded studies with lung transplant candidates, the sensitivity analyses showed even bigger differences: $V_{\mathrm{O}_{2}}^{\prime},-4.26 \mathrm{~mL} \cdot \mathrm{min}^{-1} \cdot \mathrm{kg}^{-1}$ (95\% CI -5.50 to $\left.-3.02 \mathrm{~mL} \cdot \mathrm{kg}^{-1} \cdot \mathrm{min}^{-1}, \mathrm{p}<0.00001\right) ; \mathrm{W}_{\max },-26.6 \mathrm{~W}$ (95\% CI -32.1 to $-21.1 \mathrm{~W}$, $\mathrm{p}<0.00001)$; and $\mathrm{O}_{2}$ pulse, $-2.04 \mathrm{~mL} \cdot$ beat $^{-1}\left(95 \% \mathrm{CI}-2.92\right.$ to $-1.15 \mathrm{~mL} \cdot$ beat $\left.^{-1}, \mathrm{p}<0.0001\right)$.

Conclusion Exercise tolerance was significantly lower in patients with COPD-PH than in patients with COPD-nonPH, particularly in nontransplant candidates.

Introduction

COPD is a common, preventable and treatable disease that is characterised by airflow limitation and persistent respiratory symptoms caused by exposure to significant amounts of cigarette smoke or noxious particles [1]. Pulmonary hypertension (PH) is a frequent complication in patients with COPD [1, 2], and it is associated with increased risk for hospitalisation, worse clinical course and increased mortality [3, 4]. The prevalence of $\mathrm{PH}$ in patients with COPD is not negligible; it has been reported to range between $23 \%$ and $91 \%$, depending on the diagnostic criteria used to define it and the severity of the disease [5-7]. In most cases, the severity of $\mathrm{PH}$ is usually moderate, and right ventricular function is not impacted.

Patients with COPD show reduced exercise tolerance in comparison to healthy subjects due to several factors, summarised as follows: 1) imbalance between ventilatory capacity and demand; 2) imbalance 
between oxygen supply to the respiratory and peripheral muscles and demand; and 3) peripheral muscle dysfunction [8].

The presence of $\mathrm{PH}$ has been hypothesised to further decrease exercise tolerance because it adds cardiovascular limitation to the aforementioned mechanisms, but these results are inconclusive. CutTICA et al. studied patients with advanced COPD, who were also lung transplant candidates; they reported that $\mathrm{PH}$ resulted in significant functional impairment measured by the 6-min walk test (6MWT) and was associated with an increased risk of mortality [9]. Recently, these findings were confirmed in a study by BLANCO et al. who found that patients with COPD-PH walked nearly $100 \mathrm{~m}$ less than patients with COPD-nonPH [10]. However, other similar studies did not report significant differences in the 6MWT results between patients with COPD-PH and COPD-nonPH [11-13].

The cardiopulmonary exercise test (CPET) is the gold standard for assessing exercise tolerance and provides additional information about cardiopulmonary function. In patients with COPD, the severity of the disease is determined based on symptoms and spirometry results; however, a pulmonary function test at rest does not accurately predict the grade of tolerance on exertion [14]. The inability to increase ventilation to levels that allow an adequate gas exchange is one of the mechanisms that could explain dyspnoea on exertion. This phenomenon can be observed on CPET, and it is usually interpreted as a ventilatory limitation [15].

Additionally, the literature describes the relevance of adding the CPET results to the specific evaluation of patients with $\mathrm{PH}$. The $6^{\text {th }}$ World Symposium on Pulmonary Hypertension (WSPH) recommends using CPET for a more elaborated distinction between respiratory versus circulatory limitation to discriminate between different forms of $\mathrm{PH}[16,17]$. This recommendation is mainly used to discriminate between $\mathrm{PH}$ group 1 with an exhausted circulatory reserve (predominant haemodynamic profile) versus $\mathrm{PH}$ group 3 with an exhausted ventilatory reserve (predominant obstructive/restrictive pattern) [17]. This distinction is based on the results shown by Boerrigter et al., who showed that patients with COPD and severe PH had an exhausted circulatory reserve at the end of the exercise with a low arterial carbon dioxide tension $\left(P_{\mathrm{aCO}_{2}}\right)$, whereas their breathing reserve was maintained [18]. In contrast, patients with COPD with moderate $\mathrm{PH}$ or without $\mathrm{PH}$ showed exercise limitation of ventilatory origin with an arterial $P_{\mathrm{aCO}}$ increase and exhaustion of the breathing reserve at the end of the exercise, whereas their circulatory reserve was maintained [18].

Oxygen uptake $\left(V_{\mathrm{O}_{2}}^{\prime}\right)$ is the main parameter that is obtained in the CPET. $V_{\mathrm{O}_{2}}^{\prime}$ at peak exercise $\left(V_{\mathrm{O}_{2 \text { peak }}}^{\prime}\right)$ is one of the most important prognostic factors for patients with COPD, and it is a strong predictor of mortality [19, 20]. The effect of the presence of $\mathrm{PH}$ on $V_{\mathrm{O}_{2 \text { pak }}}^{\prime}$ in patients with COPD is unclear. While some authors reported a reduction of $V^{\prime}{ }_{\mathrm{O}_{2 p e a k}}$ in CPET $[10,11]$, others did not find any significant difference between patients with COPD-PH and patients with COPD-nonPH [12, 13, 21]. Accordingly, our objective was to carry out a systematic review with meta-analysis to determine if, in patients with COPD, the presence of $\mathrm{PH}$ decreases exercise tolerance.

\section{Methods}

\section{Protocol and registration}

We performed a systematic review using Preferred reporting items for systematic reviews and meta-analyses (PRISMA) guidelines [22]. The meta-analysis was designed and performed in accordance with the Meta-analysis of Observational Studies in Epidemiology (MOOSE) [23].

\section{Criteria for considering the studies in this review}

We included randomised clinical trials (RCTs) or observational studies (cross-sectional, longitudinal, casecontrol and cohort) in adults of either gender with any degree of COPD. The included studies aimed to determine the effect of $\mathrm{PH}$ on exercise tolerance in patients with COPD. Accordingly, all the studies had at least one group of patients with COPD-PH and one group of patients with COPD-nonPH. PH was considered when echocardiography showed a systolic pulmonary arterial pressure (sPAP) $>40 \mathrm{mmHg}$ or when right heart catheterisation (RHC) showed a mean PAP (mPAP) $\geqslant 25 \mathrm{mmHg}$. Additionally, the studies reported on the ventilatory and cardiocirculatory outcomes of exercise tolerance that were obtained in the CPET.

The main outcome was exercise tolerance, as assessed by $V_{\mathrm{O}_{2 \text { peak }}}^{\prime}$ and maximum workload $\left(\mathrm{W}_{\max }\right)$ in the CPET. The secondary outcomes were $\mathrm{O}_{2}$ pulse, minute ventilation $\left(V_{\mathrm{E}}^{\prime}\right)$, minute ventilation/carbon dioxide production $\left(V_{\mathrm{E}}^{\prime} / V_{\mathrm{CO}_{2}}^{\prime}\right)$ slope and ventilatory reserve. The test should be performed on an electronically braked cycle ergometer with the patients breathing ambient air. The equipment should have been calibrated 
before every test, and the physiological variables (main outcomes) must have been measured breath-by-breath.

We excluded all articles that did not follow the Global Initiative for Chronic Obstructive Lung Disease (GOLD) criteria for COPD diagnosis or the European Society of Cardiology and European Respiratory Society (ESC/ERS) task force or the American Heart Association (AHA) guidelines for PH as well as articles that did not follow the international guidelines for performing CPET.

\section{Search strategies and data resources}

We reviewed five databases: Embase, PubMed/MEDLINE, CINAHL, Web of Science and Cochrane Central Register of Controlled Trials (CENTRAL) from their inception to 19 September 2020 and conducted manual searches using the followings terms: 1) For condition: Pulmonary Hypertension [MESH] OR Pulmonary Artery Hypertension OR Pulmonary Arterial Hypertension OR Pulmonary Artery Pressure OR Pulmonary Arterial Pressure OR Lung artery pressure OR Lung pressure OR Pulmonary Artery Systolic Pressure OR Pulmonary Heart Disease [MESH] OR Pulmonary Vascular Disease OR Right Ventricular Systolic Pressure OR mPAP AND Chronic Obstructive Pulmonary Disease [MESH]; 2) For the main outcome: Cardiopulmonary Exercise Test [MESH] OR Exercise Tolerance OR Exercise Test OR Exercise Capacity OR Cardiorespiratory Fitness OR Oxygen Consumption [MESH] OR Oxygen uptake OR Physical Fitness OR Aerobic Capacity. We imposed no language or publication restrictions.

The terms selected were combined using Boolean logical operators (OR, AND, NOT). In addition, we did a manual search of the references that were included in the selected articles. All the references were analysed in Rayyan software, a web-based tool [24].

\section{Reviewing procedure and study selection}

The review was performed independently by two investigators ( $\mathrm{R}$. Torres-Castro and L. Vasconcello-Castillo) who have experience conducting literature reviews and meta-analyses. The first step consisted of reviewing the titles and abstracts of all the references retrieved by the database searches (R. Torres-Castro and L. Vasconcello-Castillo). We ordered all articles that were deemed potentially eligible by at least one of the reviewers. In the second step, the retrieved full texts were evaluated and a decision on inclusion or exclusion was made according to the predefined selection criteria (R. Torres-Castro and L. Vasconcello-Castillo). Any disagreement in any step was solved by a third reviewer (J. Vilaró). All studies that did not fulfil the predefined criteria were excluded, and their bibliographic details were listed with the specific reason for exclusion. We included studies if they fulfilled the following criteria: 1) original research; 2) patients with a diagnosis of COPD with and without $\mathrm{PH}$; 3) reported parameters obtained from CPET; 4) full text available without language restriction.

\section{Data extraction and methodological quality assessment}

Two investigators (R. Torres-Castro and L. Vasconcello-Castillo) extracted the data independently and in duplicate using a standardised protocol and reporting forms. The following information was extracted from each included study: design, population characteristics, pulmonary function in the predicted values of forced expiratory volume in $1 \mathrm{~s}\left(\mathrm{FEV}_{1}\right)$ and diffusing capacity of the lung for carbon monoxide $\left(D_{\mathrm{LCO}}\right)$, mPAP, and exercise tolerance parameters $\left(V_{\mathrm{O}_{2 \text { peak }}}^{\prime}, \mathrm{W}_{\text {max }}, \mathrm{O}_{2}\right.$ pulse, $V_{\mathrm{E}}^{\prime}, V_{\mathrm{E}}^{\prime} / V_{\mathrm{CO}_{2}}^{\prime}$ slope and ventilatory reserve). If some relevant data were not in the article, the authors were contacted to request the information.

The risk of bias of the included studies was assessed using the Quality in Prognosis Studies (QUIPS) risk of bias tool [25]. To minimise bias, the studies were graded independently by two reviewers (R. Torres-Castro and E. Gimeno-Santos). Any discrepancy in assessment was resolved by a third reviewer (J. Vilaró).

\section{Data synthesis and analysis}

We reported summaries of the association between the prognostic factors and the outcomes for each study in terms of the mean differences of absolute values. We obtained combined measurements of effect for each primary outcome through meta-analysis under a random-effects model, due to the expected heterogeneity between the studies in prognostic reviews [26]. Statistical heterogeneity was measured through the $I^{2}$ statistic and classified as low $\left(I^{2}<25 \%\right)$, moderate $\left(I^{2} 25-50 \%\right)$ or high $\left(I^{2}>50 \%\right)$ [27]. A sensitivity analysis was conducted by excluding the studies with lung transplant candidates from the meta-analysis due to the physical, respiratory and functional severity described in patients with end-stage COPD [12]. 
Results

Study selection

The flow chart of the study selection process is shown in figure 1; from the 4915 identified references, seven articles were finally included [10-12, 18, 21, 28, 29]. Of the 16 studies assessed as full text, we excluded five for being conference abstracts and four for not meeting the diagnosis criteria.

\section{Characteristics of the included studies}

Four studies were conducted in Europe [10, 18, 21, 28], one was conducted in Israel [12], one was conducted in the USA [11] and one was conducted in China [29]. Regarding the design, three studies were retrospective $[11,12,21]$, three were cross-sectional $[10,18,28]$ and one was prospective [29]. None of the included studies was an RCT. Two studies were restricted to lung transplant candidates $[11,12]$. The characteristics of the included studies are summarised in table 1.

\section{Participants}

In total, 661 participants were enrolled in the included studies. Among the studies, the sample size ranged from 25 [21] to 180 [29]. A total of 257 (38.9\%) of the participants had PH (COPD-PH group) and 404 (61.1\%) did not have PH (COPD-nonPH group). The mean age of the patients was 64.6 \pm 7.1 years in the COPD-PH group and $64.3 \pm 7.1$ years in the COPD-nonPH group. The $\mathrm{FEV}_{1} \%$ pred was $35.6 \pm 15.5 \%$ in the COPD-PH group and $42.2 \pm 15.4 \%$ in the COPD-nonPH group ( $\mathrm{p}=0.17)$. The $D_{\mathrm{LCO}} \%$ pred was $35.3 \pm 13.1 \%$ in the COPD-PH group and $49.6 \pm 17.1 \%$ in the COPD-nonPH group, with significant differences between groups $(\mathrm{p}=0.01)$. A summary of the patients' characteristics is presented in table 1 .

Risk of bias assessment

Results of the risk of bias assessment of individual studies are presented in table 2. The majority of the studies were rated as having a low-to-moderate risk of bias. All the studies had a low risk of bias regarding

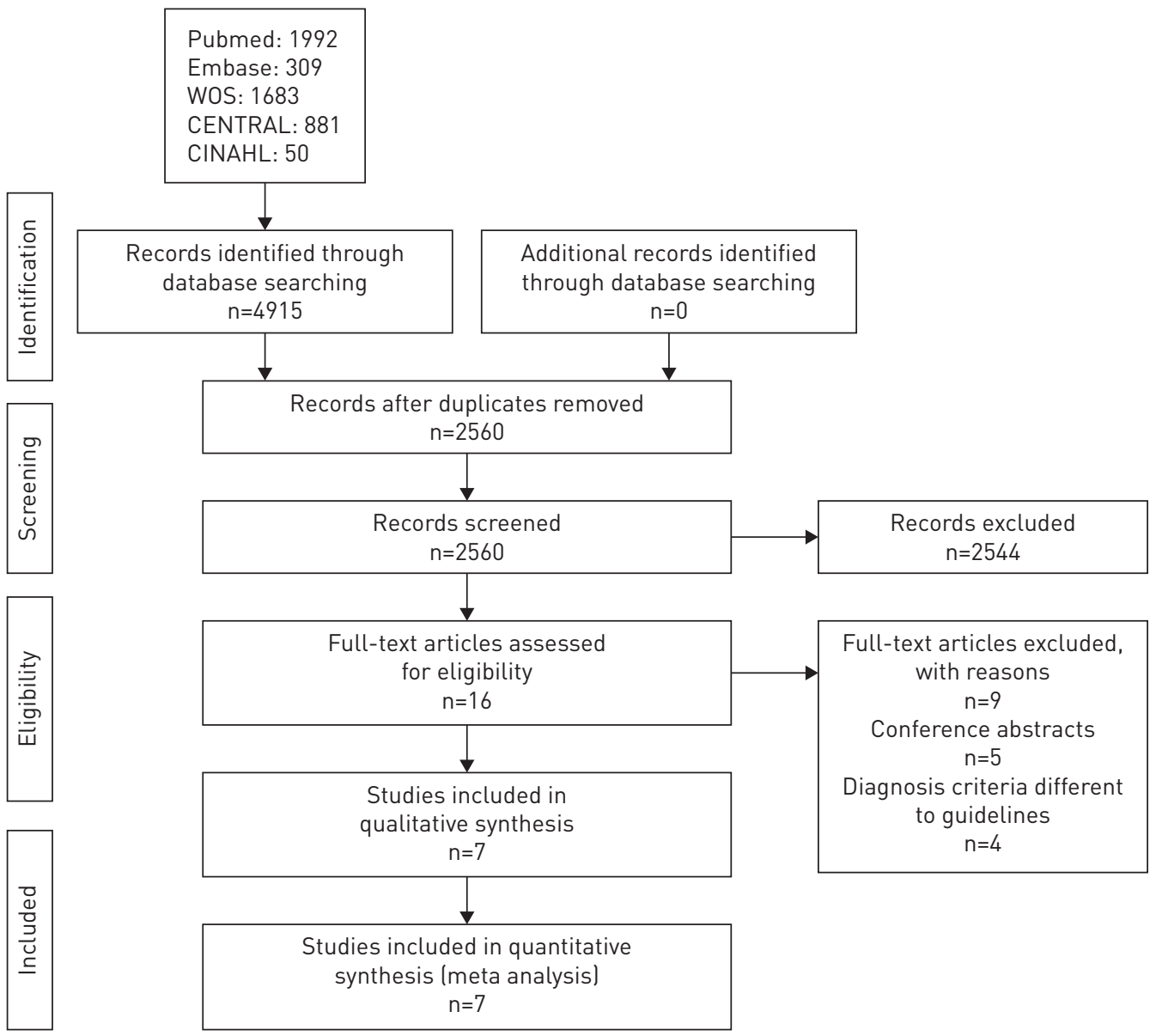

FIGURE 1 PRISMA flowchart of the selection of studies. 


\begin{tabular}{|c|c|c|c|c|c|c|c|c|c|}
\hline First author [ref.] & Design & Group & $\begin{array}{l}\text { Sample } \\
\text { size } n\end{array}$ & Age years & $\begin{array}{c}\mathrm{BMI} \\
\mathrm{Kg} \cdot \mathrm{m}^{-2}\end{array}$ & $\begin{array}{l}\mathrm{FEV}_{1} \% \\
\text { pred }\end{array}$ & $\begin{array}{l}D_{\text {Lco }} \% \\
\text { pred }\end{array}$ & $\begin{array}{c}P_{\mathrm{aO}_{2}} \\
\mathrm{mmHg}\end{array}$ & $\begin{array}{l}\mathrm{mPAP} \\
\mathrm{mmHg}\end{array}$ \\
\hline \multicolumn{10}{|c|}{$\begin{array}{l}\text { Studies without lung } \\
\text { transplant candidates }\end{array}$} \\
\hline \multirow[t]{2}{*}{ HoLverDA [21] } & Retrospective & COPD-nonPH & 15 & $66 \pm 10$ & $25 \pm 3$ & $49 \pm 19$ & $50 \pm 13$ & $74.3 \pm 10.5$ & $18 \pm 3$ \\
\hline & & COPD-PH & 10 & $64 \pm 11$ & $22 \pm 4$ & $62 \pm 31$ & $37 \pm 14$ & $57.0 \pm 15.0$ & $33 \pm 6$ \\
\hline \multirow[t]{2}{*}{ BoERRIGTER [18] } & Cross-sectional & COPD-nonPH & 24 & $62 \pm 14$ & $25 \pm 2$ & $49 \pm 18$ & $50 \pm 14$ & $71 \pm 11$ & $18.5 \pm 3.1$ \\
\hline & & COPD-PH & 23 & $67 \pm 9$ & $26 \pm 4$ & $51 \pm 19$ & $38 \pm 15$ & $57 \pm 11$ & $39.1 \pm 11.9$ \\
\hline \multirow[t]{2}{*}{ SKJøRTEN [28] } & Cross-sectional & COPD-nonPH & 71 & $64.6 \pm 6$ & $25 \pm 4$ & $47 \pm 16$ & $57 \pm 19$ & $74 \pm 9$ & $18 \pm 3.5$ \\
\hline & & COPD-PH & 22 & $61 \pm 8$ & $25 \pm 6$ & $29 \pm 9$ & $30 \pm 14$ & $61 \pm 11$ & $28.7 \pm 4.6$ \\
\hline \multirow[t]{2}{*}{ XIONG [29] } & Prospective & COPD-nonPH & 98 & $64.9 \pm 7.1$ & $23.8 \pm 5.9$ & $44.9 \pm 20.2$ & NR & $60.8 \pm 16.8$ & $19.7 \pm 20.5$ \\
\hline & & COPD-PH & 82 & $67.3 \pm 6.7$ & $20.1 \pm 6.0$ & $42.3 \pm 22.7$ & NR & $48.1 \pm 16.0$ & $32.0 \pm 20.6$ \\
\hline \multirow[t]{2}{*}{ Blanco [10] } & Cross-sectional & COPD-nonPH & 109 & $68 \pm 8$ & $28 \pm 5$ & $51 \pm 16$ & $59 \pm 17$ & $72 \pm 10$ & NR \\
\hline & & COPD-PH & 65 & $66 \pm 8$ & $26 \pm 4$ & $32 \pm 11$ & $40 \pm 15$ & $67 \pm 12$ & NR \\
\hline \multicolumn{10}{|c|}{$\begin{array}{l}\text { Studies with lung } \\
\text { transplant candidates }\end{array}$} \\
\hline \multirow[t]{2}{*}{ THIRAPATARAPONG [11] } & Retrospective & COPD-nonPH & 67 & $59(55-61)$ & $23 \pm 3.9$ & $20 \pm 7$ & $28(20-43)$ & $72.7 \pm 17$ & $20.9 \pm 3.1$ \\
\hline & & COPD-PH & 31 & $59(57-62)$ & $22.7 \pm 4$ & $18 \pm 6$ & $25(20-26)$ & $67.0 \pm 20$ & $30.2 \pm 5.0$ \\
\hline \multirow[t]{2}{*}{ ADIR [12] } & Retrospective & COPD-nonPH & 20 & $61.1 \pm 4.4$ & $22.1 \pm 4.8$ & $24.9 \pm 8.9$ & $35.2 \pm 17.3$ & NR & $20.2 \pm 2.2$ \\
\hline & & COPD-PH & 24 & $59.4 \pm 6.3$ & $25.5 \pm 4.7$ & $25.9 \pm 11.6$ & $39.2 \pm 15.9$ & NR & $28.6 \pm 2.7$ \\
\hline
\end{tabular}

Data are presented as mean \pm SD or median (interquartile range), unless otherwise stated. BMI: body mass index; FEV ${ }_{1}$ : forced expiratory volume in $1 \mathrm{~s}$; $D_{\mathrm{LCO}}$ : diffusing capacity of the lung for carbon monoxide; $P_{\mathrm{aO}_{2}}$ : arterial oxygen tension; mPAP: mean pulmonary arterial pressure; PH: pulmonary hypertension; NR: not reported.

“study participation” and “outcome measurements”. In the categories, “study attrition”, "prognostic factor measurement" and "statistical analysis reporting”, most of the studies varied between a low risk of bias and a moderate risk of bias because the diagnostic criteria of COPD and PH and the main outcomes obtained in the CPET are well established by the clinical guidelines, and there is consensus for their application. Regarding the "study confounding" category, most of studies varied between a moderate risk of bias and a high risk of bias.

\section{Main findings}

Primary outcomes

Peak oxygen consumption

All seven studies examined exercise tolerance considering $V_{\mathrm{O}_{2 \mathrm{pak}}}^{\prime}$ in $\mathrm{mL} \cdot \mathrm{kg}^{-1} \cdot \mathrm{min}^{-1}[10-12,18,21,28,29]$ (table 3). These studies compared 257 participants with COPD-PH versus 404 participants with COPD-nonPH. The heterogeneity of the comparison was high $\left(\mathrm{I}^{2}=87 \%\right)$. Patients with COPD-PH had, on average, $-3.09 \mathrm{~mL} \cdot \mathrm{min}^{-1} \cdot \mathrm{kg}^{-1}$ (95\% CI -4.74 to $-1.43 \mathrm{~mL} \cdot \mathrm{kg}^{-1} \cdot \mathrm{min}^{-1}$ ) of $V_{\mathrm{O}_{2 p a k}}^{\prime}$ in comparison to patients with COPD-nonPH ( $\mathrm{p}=0.0003$ ). If we exclude the studies with lung transplant candidates, the average difference in $V_{\mathrm{O}_{2 \text { peak }}}^{\prime}$ between the two groups was even greater, $-4.26 \mathrm{~mL} \cdot \mathrm{min}^{-1} \cdot \mathrm{kg}^{-1}(95 \% \mathrm{CI}-5.50$ to $-3.02 \mathrm{~mL} \cdot \mathrm{kg}^{-1} \cdot \mathrm{min}^{-1}, \mathrm{p}<0.00001, \mathrm{I}^{2}=61 \%$ ) (figure 2 ).

\section{TABLE 2 Risk of bias assessment summary using the Quality in Prognosis Studies tool}

\begin{tabular}{|c|c|c|c|c|c|c|}
\hline First author [ref.] & $\begin{array}{c}\text { Study } \\
\text { participation }\end{array}$ & $\begin{array}{l}\text { Study } \\
\text { attrition }\end{array}$ & $\begin{array}{l}\text { Prognostic factor } \\
\text { measurement }\end{array}$ & $\begin{array}{c}\text { Outcome } \\
\text { measurement }\end{array}$ & $\begin{array}{c}\text { Study } \\
\text { confounding }\end{array}$ & $\begin{array}{l}\text { Statistical analysis } \\
\text { reporting }\end{array}$ \\
\hline Holverda [21] & Low & Moderate & Low & Low & Moderate & Low \\
\hline BOERRIGTER [18] & Low & Low & Low & Low & Moderate & Low \\
\hline THIRAPATARAPONG [11] & Low & Moderate & Low & Low & High & Low \\
\hline AdIR [12] & Low & Low & Moderate & Low & High & Moderate \\
\hline SKJøRTEN [28] & Low & Low & Low & Low & Low & Low \\
\hline XIONG [29] & Low & Low & Low & Low & Moderate & Low \\
\hline BLANCO [10] & Low & Moderate & Moderate & Low & Moderate & Low \\
\hline
\end{tabular}


TABLE 3 Exercise tolerance variables: comparison between patients with COPD-nonPH versus patients with COPD-PH

\begin{tabular}{|c|c|c|c|c|c|c|c|c|}
\hline First author [ref.] & Participants & $\begin{array}{l}\text { Sample } \\
\text { size } n\end{array}$ & $\begin{array}{c}V^{\prime}{ }_{\mathrm{O}_{2 \text { peak }}} \\
\mathrm{mL} \cdot \mathrm{Kg}^{-1} \cdot \mathrm{min}^{-1}\end{array}$ & $\mathrm{~W}_{\max } \mathrm{W}$ & $\begin{array}{l}\mathrm{O}_{2} \text { pulse }^{-1} \\
\mathrm{~mL} \cdot \text { beat }^{-1}\end{array}$ & $\begin{array}{c}V_{E}^{\prime} \\
L \cdot \min ^{-1}\end{array}$ & $\begin{array}{l}V_{\mathrm{E}}^{\prime} / V^{\prime} \mathrm{CO}_{2} \\
\text { slope }\end{array}$ & $\begin{array}{l}\text { Ventilatory } \\
\text { reserve \% }\end{array}$ \\
\hline \multicolumn{9}{|c|}{$\begin{array}{l}\text { Studies without lung } \\
\text { transplant candidates }\end{array}$} \\
\hline \multirow[t]{2}{*}{ HoLverDa [21] } & COPD-nonPH & 15 & $13 \pm 3.8$ & $65 \pm 25$ & $7.6 \pm 1.6$ & $37 \pm 10$ & $36 \pm 11$ & NR \\
\hline & COPD-PH & 10 & $13.2 \pm 5.1$ & $47 \pm 20$ & $6.6 \pm 2.4$ & $46 \pm 24$ & $51 \pm 23$ & NR \\
\hline \multirow[t]{2}{*}{ BoeRRIGTER [18] } & COPD-nonPH & 24 & $14 \pm 4.2$ & $71 \pm 47$ & $8.3 \pm 3.0$ & $40.8 \pm 13$ & NR & $22.9 \pm 20.7$ \\
\hline & COPD-PH & 23 & $9.8 \pm 2.9$ & $36 \pm 26$ & $6.8 \pm 2.5$ & $34.7 \pm 16.3$ & NR & $33.1 \pm 17.0$ \\
\hline \multirow{2}{*}{ SKJøRTEN [28] } & COPD-nonPH & 71 & $17.6 \pm 4.3$ & $72 \pm 31$ & $9.4 \pm 2.9$ & $46 \pm 15$ & NR & $9 \pm 22$ \\
\hline & COPD-PH & 22 & $13.9 \pm 3$ & $40 \pm 21$ & $7.5 \pm 2.1$ & $35 \pm 12$ & NR & $-7 \pm 19$ \\
\hline \multirow[t]{2}{*}{ XIONG [29] } & COPD-nonPH & 98 & $20.4 \pm 7.2$ & NR & NR & NR & NR & NR \\
\hline & COPD-PH & 82 & $14.6 \pm 6.5$ & NR & NR & NR & NR & NR \\
\hline \multirow[t]{2}{*}{ BLANCO [10] } & COPD-nonPH & 109 & $15 \pm 3$ & $68 \pm 27$ & $9.4 \pm 2.5$ & $46 \pm 15$ & NR & $12.3 \pm 21.3$ \\
\hline & COPD-PH & 65 & $10 \pm 2$ & $43 \pm 20$ & $6.5 \pm 2.1$ & $31 \pm 11$ & NR & $5.9 \pm 24.8$ \\
\hline \multicolumn{9}{|c|}{$\begin{array}{l}\text { Studies with lung } \\
\text { transplant candidates }\end{array}$} \\
\hline \multirow{2}{*}{$\begin{array}{l}\text { THIRAPATARAPONG } \\
{[11]}\end{array}$} & COPD-nonPH & 67 & $11.3 \pm 4.1$ & $21 \pm 15$ & $5.2 \pm 1.7$ & $22 \pm 10$ & $36 \pm 8$ & $17(11-25)$ \\
\hline & COPD-PH & 31 & $9.5 \pm 2.5$ & $15 \pm 9$ & $5.0 \pm 1.7$ & $18 \pm 7$ & $36 \pm 7$ & $13(-2-25)$ \\
\hline \multirow[t]{2}{*}{ ADIR [12] } & COPD-nonPH & 20 & $9.5 \pm 2.9$ & $35.7 \pm 19$ & $5.5 \pm 2.1$ & $26 \pm 6.4$ & $44.1 \pm 7.8$ & $13.5 \pm 15.0$ \\
\hline & COPD-PH & 24 & $9.3 \pm 2.3$ & $40.4 \pm 20.4$ & $5.7 \pm 2.3$ & $27.9 \pm 13.1$ & $37.6 \pm 7.3$ & $19.4 \pm 28.3$ \\
\hline
\end{tabular}

Data are presented as mean $\pm \mathrm{SD}$ or median (interquartile range), unless otherwise stated. $V^{\prime}{ }_{\mathrm{O}_{\text {2peak }}}$ : peak oxygen uptake; $\mathrm{W}_{\text {max }}$ : maximum workload; $V_{\mathrm{E}}^{\prime}$ : minute ventilation; $V^{\prime}{ }_{E} / V^{\prime} \mathrm{CO}_{2}$ : minute ventilation/carbon dioxide production; PH: pulmonary hypertension; NR: not reported.

Maximum workload

Five studies examined $\mathrm{W}_{\max }$ in $\mathrm{W}[10,12,18,21,28]$ (table 3). These studies compared 144 participants with COPD-PH versus 239 participants with COPD-nonPH. The heterogeneity of the comparison was high $\left(\mathrm{I}^{2}=84 \%\right)$. Patients with COPD-PH had a $\mathrm{W}_{\max }-20.5 \mathrm{~W}(95 \% \mathrm{CI}-34.4$ to $-6.5 \mathrm{~W})$ lower than patients with COPD-nonPH $(\mathrm{p}=0.004)$. If we exclude the studies with lung transplant candidates, the difference between the two groups was even greater: $-26.6 \mathrm{~W}\left(95 \% \mathrm{CI}-32.1\right.$ to $\left.-21.1 \mathrm{~W}, \mathrm{p}<0.00001, \mathrm{I}^{2}=0 \%\right)$ (figure 3).

\section{Secondary outcomes}

Oxygen pulse

Six studies examined $\mathrm{O}_{2}$ pulse [10-12, 18, 21, 28] (table 3). These studies compared 175 participants with COPD-PH versus 306 participants with COPD-nonPH participants. The heterogeneity of the comparison was high $\left(\mathrm{I}^{2}=86 \%\right)$. Patients with $\mathrm{COPD}-\mathrm{PH}$ had an $\mathrm{O}_{2}$ pulse $-1.24 \mathrm{~mL}^{\text {beat }}{ }^{-1}$ (95\% CI -2.40 to $-0.09 \mathrm{~mL} \cdot$ beat $\left.^{-1}\right)$ lower than the COPD-nonPH group $(\mathrm{p}=0.03)$. If we exclude the studies with lung transplant candidates, the difference between the two groups was $-2.04 \mathrm{~mL} \cdot$ beat $^{-1}$ (95\% CI -2.92 to $-1.15 \mathrm{~mL} \cdot$ beat $^{-1}, \mathrm{p}<0.00001, \mathrm{I}^{2}=55 \%$ ) (figure 4 ).

\section{Minute ventilation}

Six studies examined maximum $V_{E}^{\prime}[10-12,18,21,28]$ (table 3). These studies compared 175 participants with COPD-PH versus 306 participants with COPD-nonPH. Both groups had similar maximum $V_{\mathrm{E}}^{\prime}$ values (mean difference $-5.54 \mathrm{~L} \cdot \mathrm{min}^{-1}$; 95\% CI $-11.65-0.57 \mathrm{~L} \cdot \mathrm{min}^{-1}, \mathrm{p}=0.08$ ). The heterogeneity of the comparison was high $\left(\mathrm{I}^{2}=85 \%\right)$. If we exclude the studies with lung transplant candidates, patients with COPD-PH had a $V_{E}^{\prime}-8.58 \mathrm{~L} \cdot \mathrm{min}^{-1}\left(95 \% \mathrm{CI}-15.54\right.$ to $-1.62 \mathrm{~L} \cdot \mathrm{min}^{-1}$, p=0.02, $\left.\mathrm{I}^{2}=73 \%\right)$ lower than patients with COPD-nonPH (figure 5).

$V^{\prime}{ }_{E} / V^{\prime} \mathrm{CO}_{2}$ slope

Three studies examined the $V_{\mathrm{E}}^{\prime} / V^{\prime} \mathrm{CO}_{2}$ slope $[11,12,21]$ (table 3). These studies compared 65 participants with COPD-PH versus 102 participants with COPD-nonPH. Both groups had similar $V_{\mathrm{E}}^{\prime} / V^{\prime} \mathrm{CO}_{2}$ slope values (mean difference -0.33 ; 95\% CI $-7.61-6.95$, $\mathrm{p}=0.93$ ). The heterogeneity of the comparison was high $\left(\mathrm{I}^{2}=80 \%\right.$ ) (figure 6). The analysis excluding the lung transplant candidates was not performed due to the insufficient number of studies reporting this outcome. 


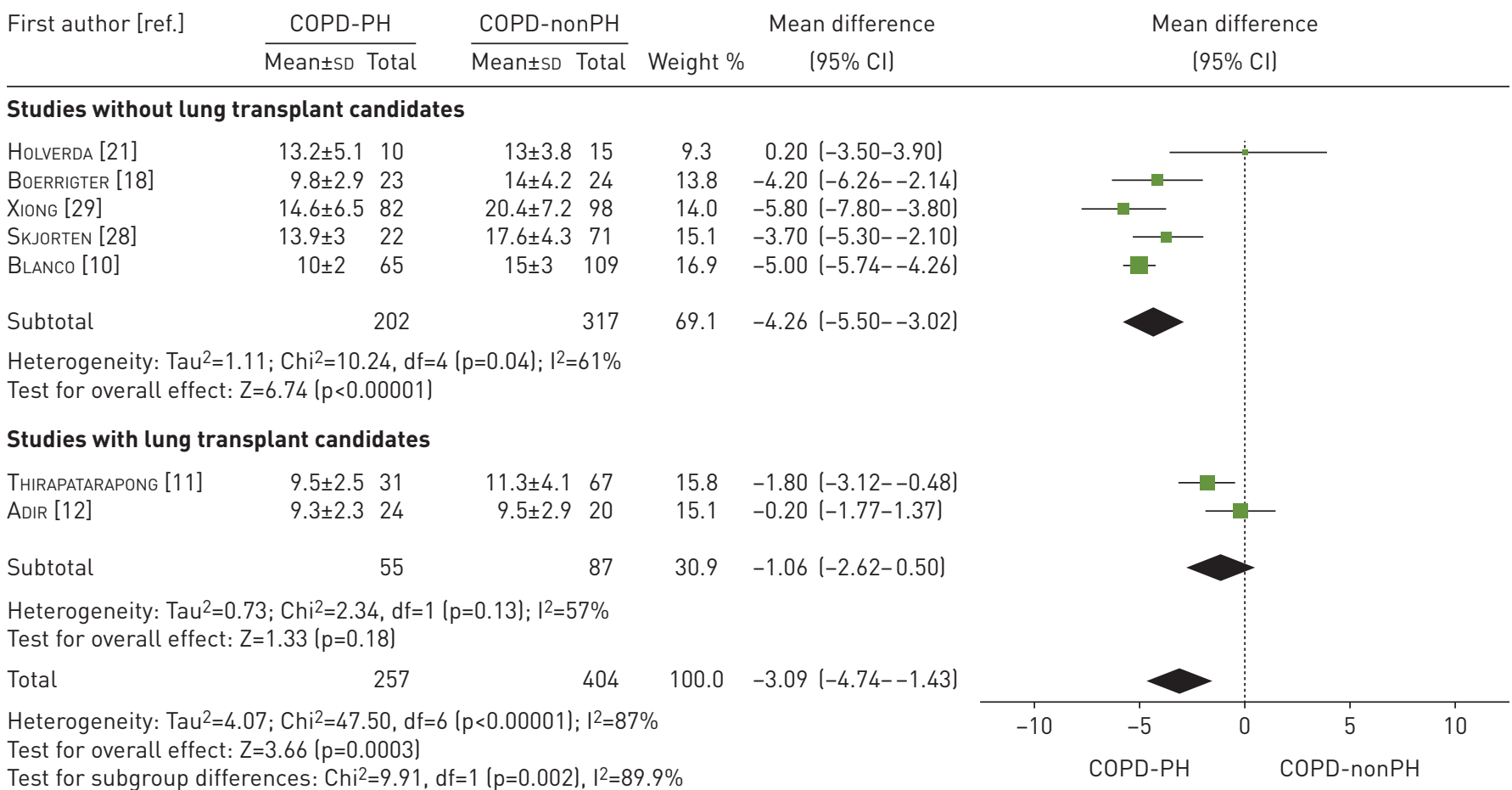

FIGURE 2 Mean difference (inverse variance method, random-effects model) for mean peak oxygen consumption for patients with COPD-PH and patients with COPD-nonPH. PH: pulmonary hypertension.

First author [ref.]

$$
\frac{\text { COPD-PH }}{\text { Mean } \pm \text { SD Total }} \frac{\text { COPD-nonPH }}{\text { Mean } \pm \text { SD Total Weight } \%} \quad \begin{gathered}
\text { Mean difference } \\
(95 \% \mathrm{Cl})
\end{gathered}
$$

Mean difference

(95\% Cl)

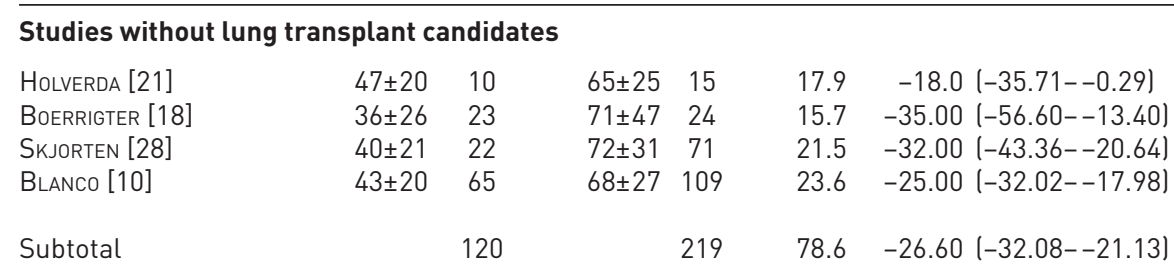

Heterogeneity: $\operatorname{Tau}^{2}=0.00 ; \mathrm{Chi}^{2}=2.55, \mathrm{df}=3(\mathrm{p}=0.47) ; \mathrm{I}^{2}=0 \%$

Test for overall effect: $Z=9.52(p<0.00001)$

Studies with lung transplant candidates

ADIR [12]

$40.4 \pm 20.424$

$35.7 \pm 19 \quad 20$

21.4

$4.70(-6.96-16.36)$

Subtotal

24

20

21.4

$4.70(-6.96-16.36)$

Heterogeneity: Not applicable

Test for overall effect: $Z=0.79(p=0.43)$

Total

144

$239 \quad 100.0-20.48(-34.42--6.54)$

Heterogeneity: $\operatorname{Tau}^{2}=201.40 ; \mathrm{Chi}^{2}=25.24, \mathrm{df}=4(\mathrm{p}<0.00001) ; \mathrm{I}^{2}=84 \%$

Test for overall effect: $Z=2.88$ ( $p=0.004)$

Test for subgroup differences: $\mathrm{Chi}^{2}=22.68, \mathrm{df}=1(\mathrm{p}<0.00001), \mathrm{I}^{2}=95.6 \%$

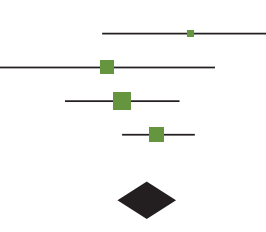

FIGURE 3 Mean difference (inverse variance method, random-effects model) for mean maximum workload for patients with COPD-PH and patients with COPD-nonPH. PH: pulmonary hypertension. 
First author [ref.] $\frac{\text { COPD-PH }}{\text { Mean } \pm \text { SD Total }} \quad \frac{\text { COPD-nonPH }}{\text { Mean } \pm \text { SD Total Weight } \%}$

Mean difference

Mean difference

(95\% Cl)

$(95 \% \mathrm{Cl})$

\begin{tabular}{|c|c|c|c|c|c|c|}
\hline HoLVERDA [21] & $6.6 \pm 2.4$ & 10 & $7.6 \pm 1.6$ & 15 & 14.1 & $-1.00(-2.69-0.69)$ \\
\hline BoERRIGTER [18] & $6.8 \pm 2.5$ & 23 & $8.3 \pm 3$ & 24 & 14.7 & $-1.50(-3.08-0.08)$ \\
\hline SKJORTEN [28] & $7.5 \pm 2.1$ & 22 & $9.4 \pm 2.9$ & 71 & 17.1 & $-1.90(-3.01--0.79)$ \\
\hline BLANCo [10] & $6.5 \pm 2.1$ & 65 & $9.4 \pm 2.5$ & 109 & 19.0 & $-2.90(-3.59--2.21)$ \\
\hline Subtotal & & 120 & & 219 & 65.0 & $-2.04(-2.92--1.15)$ \\
\hline
\end{tabular}

Heterogeneity: $\mathrm{Tau}^{2}=0.43 ; \mathrm{Chi}^{2}=6.61, \mathrm{df}=3(\mathrm{p}=0.09) ; \mathrm{I}^{2}=55 \%$

Test for overall effect: $Z=4.52(p<0.00001)$

Studies with lung transplant candidates

THIRAPATARAPONG [11]

$5 \pm 1.7 \quad 31$

$5.2 \pm 1.7 \quad 67$

18.8

$-0.20(-0.92-0.52)$

ADIR [12]

$5.7 \pm 2.3 \quad 24$

$5.5 \pm 2.1 \quad 20$

16.2

$0.20(-1.10-1.50)$

Subtotal

55

$87 \quad 35.0$

$-0.11(-0.74-0.53)$

Heterogeneity: $\operatorname{Tau}^{2}=0.00 ; \mathrm{Chi}^{2}=0.28, \mathrm{df}=1(\mathrm{p}=0.60) ; \mathrm{I}^{2}=0 \%$

Test for overall effect: $Z=0.33(p=0.74)$

Total

175

$306 \quad 100.0$

$-1.24(-2.40--0.09)$

Heterogeneity: $\operatorname{Tau}^{2}=1.70 ; \mathrm{Chi}^{2}=35.33, \mathrm{df}=5(\mathrm{p}<0.00001) ;\left.\right|^{2}=86 \%$

Test for overall effect: $Z=2.11(p=0.03)$

Test for subgroup differences: $\mathrm{Chi}^{2}=12.15, \mathrm{df}=1(\mathrm{p}=0.0005), \mathrm{I}^{2}=91.8 \%$

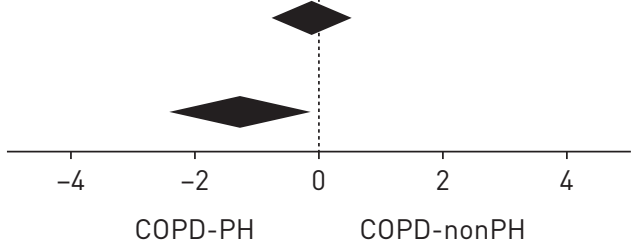

FIGURE 4 Mean difference (inverse variance method, random-effects model) for mean oxygen pulse for patients with COPD-PH and patients with COPD-nonPH. PH: pulmonary hypertension.

First author [ref.]

$$
\frac{\text { COPD-PH }}{\text { Mean } \pm \text { SD Total }} \frac{\text { COPD-nonPH }}{\text { Mean } \pm \text { SD Total Weight } \%}
$$

Mean difference

Mean difference

$(95 \% \mathrm{Cl})$

$(95 \% \mathrm{Cl})$

\section{Studies without lung transplant candidates}

\begin{tabular}{|c|c|c|c|c|c|c|}
\hline BLANCo [10] & $31 \pm 11$ & 65 & $46 \pm 15$ & 109 & 19.9 & $-15.00(-18.88--11.12$ \\
\hline BoERRIGTER [18] & $34.7 \pm 16.3$ & 23 & $40.8 \pm 13$ & 24 & 15.3 & $-6.10(-14.55-2.35)$ \\
\hline Holverda [21] & $46 \pm 24$ & 10 & $37 \pm 10$ & 15 & 8.9 & $9.00(-6.71-24.71)$ \\
\hline SKJORTEN [28] & $35 \pm 12$ & 22 & $46 \pm 15$ & 71 & 17.8 & $-11.00(-17.11--4.89)$ \\
\hline btota & & 12 & & 219 & 61.8 & $-8.58(-15.54-1.62)$ \\
\hline
\end{tabular}

Heterogeneity: $\operatorname{Tau}^{2}=33.47 ; \mathrm{Chi}^{2}=11.13, \mathrm{df}=3(\mathrm{p}=0.01) ; \mathrm{I}^{2}=73 \%$

Test for overall effect: $Z=2.42$ ( $p<0.00001)$

\section{Studies with lung transplant candidates}

\begin{tabular}{|c|c|c|c|c|c|c|}
\hline ADIR [12] & $27.9 \pm 13.1$ & 24 & $26 \pm 6.4$ & 20 & 17.9 & $1.90(-4.04-7.84)$ \\
\hline THIRAPATARAPONG [11] & $18 \pm 7$ & 31 & $22 \pm 10$ & 67 & 20.2 & $-4.00(-7.44--0.56)$ \\
\hline Subtotal & & 5 & & 87 & 38.2 & $-1.57(-7.26-4.12)$ \\
\hline
\end{tabular}

Heterogeneity: $\operatorname{Tau}^{2}=11.27 ; \mathrm{Chi}^{2}=2.84, \mathrm{df}=1(\mathrm{p}=0.09) ; \mathrm{I}^{2}=65 \%$

Test for overall effect: $Z=0.54(p=0.59)$

Total

175

$306 \quad 100.0 \quad-5.54(-11.65-0.57)$

Heterogeneity: $\mathrm{Tau}^{2}=44.96 ; \mathrm{Chi}^{2}=33.47, \mathrm{df}=5(\mathrm{p}<0.00001) ; \mathrm{I}^{2}=85 \%$

Test for overall effect: $Z=1.78(p=0.08)$

Test for subgroup differences: $\mathrm{Chi}^{2}=2.34, \mathrm{df}=1(\mathrm{p}=0.13), \mathrm{I}^{2}=57.2 \%$

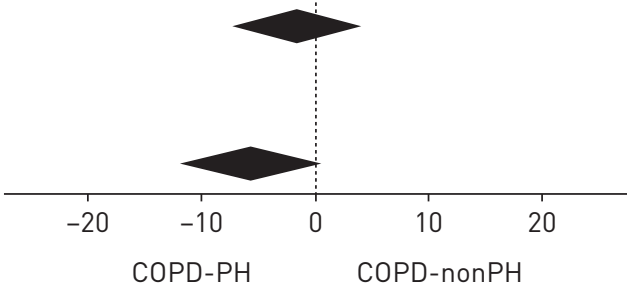

FIGURE 5 Mean difference (inverse variance method, random-effects model) for mean minute ventilation for patients with COPD-PH and patients with COPD-nonPH. PH: pulmonary hypertension. 


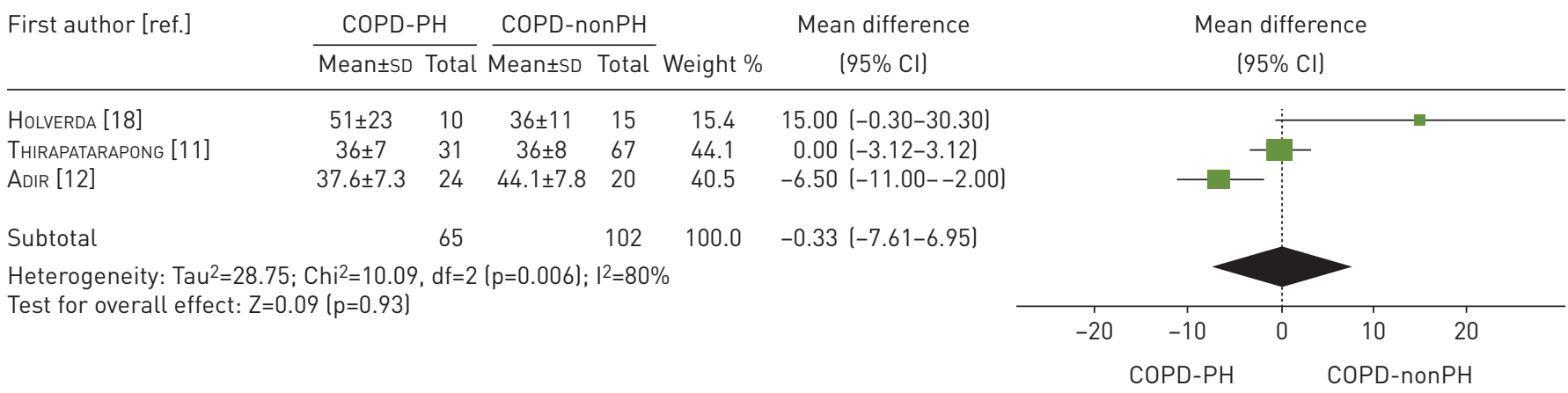

FIGURE 6 Mean difference (inverse variance method, random-effects model) for mean ventilatory equivalent for carbon dioxide at anaerobic threshold for patients with COPD-PH and patients with COPD-nonPH. PH: pulmonary hypertension.

Ventilatory reserve

Five studies examined the ventilatory reserve as a percentage of the maximum voluntary ventilation [10-12, 18, 28] (table 3). These studies compared 165 patients with COPD-PH versus 291 patients with COPD-nonPH. Both groups had similar ventilatory reserve values (mean difference $-3.08 \%$; 95\% CI $-11.33-5.16 \%, p=0.46)$. The heterogeneity of the comparison was substantial $\left(\mathrm{I}^{2}=74 \%\right)$. If we exclude the studies with lung transplant candidates, the forest plot showed a similar value for ventilatory reserve (-4.35\%; 95\% CI -17.68-8.97\%, $\mathrm{p}=0.52, \mathrm{I}^{2}=85 \%$ ) between both groups (figure 7).

\section{Discussion}

This systematic review and meta-analysis showed that the $V_{\mathrm{O}_{2 p e a k}}^{\prime}, \mathrm{W}_{\max }$ and $\mathrm{O}_{2}$ pulse values were significantly lower in the patients with COPD-PH than the patients with COPD-nonPH, such differences were mainly driven by patients with less severe COPD who were not candidates for lung transplant.

Previous studies have provided conflicting results about the effect of $\mathrm{PH}$ on exercise tolerance in patients with COPD. A potential explanation for this could be the limited sample size in most of the studies, and for this reason we undertook a meta-analysis of the reported results, achieving a sizeable number of

First author [ref.]

$\frac{\text { COPD-PH }}{\text { Mean } \pm \text { SD Total }} \frac{\text { COPD-nonPH }}{\text { Mean } \pm \text { SD Total Weight } \%} \quad \begin{gathered}\text { Mean difference } \\ (95 \% \mathrm{CI})\end{gathered}$

Mean difference (95\% Cl)

\section{Studies without lung transplant candidates}

BOERRIGTER [18]

SKJORTEN [28]

$33.1 \pm 17 \quad 23 \quad 22.9 \pm 20.7 \quad 24$

$\begin{array}{llll}-7 \pm 19 & 22 & 9 \pm 22 & 71\end{array}$

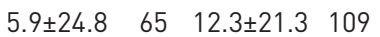

$18.7 \quad 10.20(-0.61-21.01)$

BLANCO [10]

110

204

$20.2-16.00(-25.45--6.55)$

$22.7-6.40(-13.63-0.83)$

Subtotal

$d f=2(p=0.002) ; 1^{2}=85 \%$

Heterogeneity: $\operatorname{Tau}^{2}=116.55 ; \mathrm{Chi}^{2}=12.91, \mathrm{df}=2$ ( $\left.\mathrm{p}=0.002\right) ; \mathrm{I}^{2}=85 \%$

Test for overall effect: $Z=0.64(p=0.52)$

\section{Studies with lung transplant candidates}

ADIR [12]

Subtotal
THIRAPATARAPONG [11]
$12 \pm 21$

$9.4 \pm 28.3 \quad 24 \quad 13.5 \pm 15 \quad 20$

55
87

$22.1-5.70(-13.52-2.12)$

$16.35 .90(-7.19-18.99)$

$38.3-1.14(-12.24-9.97)$

Heterogeneity: $\mathrm{Tau}^{2}=37.02 ; \mathrm{Chi}^{2}=2.22, \mathrm{df}=1(\mathrm{p}=0.14) ; \mathrm{I}^{2}=55 \%$

Test for overall effect: $Z=0.20(p=0.84)$

Total

165

291

100.0

Heterogeneity: $\mathrm{Tau}^{2}=64.26 ; \mathrm{Chi}^{2}=15.58, \mathrm{df}=4(\mathrm{p}=0.004) ; \mathrm{I}^{2}=74 \%$

Test for overall effect: $Z=0.73(p=0.46)$

Test for subgroup differences: $\mathrm{Chi}^{2}=0.13, \mathrm{df}=1(\mathrm{p}=0.72), \mathrm{I}^{2}=0 \%$
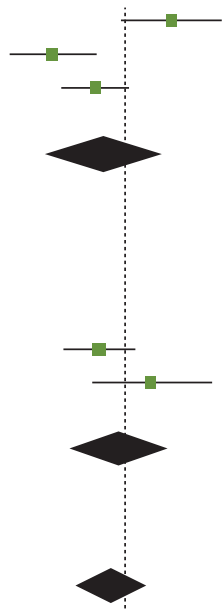

\begin{tabular}{cc|ccc} 
& & & \\
\hline-50 & -25 & 0 & 25 & 50 \\
& COPD-PH & \multicolumn{3}{c}{ COPD-nonPH }
\end{tabular}

FIGURE 7 Mean difference (inverse variance method, random-effects model) for mean ventilatory reserve for patients with COPD-PH and patients with COPD-nonPH. PH: pulmonary hypertension. 
patients that may provide more robust results. Our results confirm that in COPD-PH has a significant impact on exercise tolerance. This impact might be considered clinically relevant because the main outcome of exercise test, namely $V_{\mathrm{O}_{2 \text { peak }}}$, is an important predictor of mortality in COPD [19, 20]. In the case of $\mathrm{W}_{\max }$, the COPD-PH group showed a decrease in line with $V^{\prime}{ }_{\mathrm{O}_{2 \text { peak }}}$.

Patients with COPD-PH had lower $\mathrm{O}_{2}$ pulse than those without $\mathrm{PH}$. The $\mathrm{O}_{2}$ pulse is a surrogate for stroke volume [30] and is typically reduced in patients with cardiovascular limitation of exercise tolerance, as in pulmonary arterial hypertension (PAH) and chronic thromboembolic pulmonary hypertension (CTEPH) [31] and left heart disease [32]. The reduction in $\mathrm{O}_{2}$ pulse reflects the impairment of stroke volume and the dependency of increasing cardiac output on heart rate [33, 34]. In patients with COPD who also have PH, there is an increased afterload during exercise, which results in RV dilation [30]. The RV pressure or volume overload results in a decrease in left ventricular diastolic compliance and ejection fraction depression due to ventricular interdependence.

Two of the reviewed articles dealt with lung transplant candidates [11, 12]. We performed a sensitivity analysis by excluding these patients. The sensitivity analysis showed that reductions of $V_{\mathrm{O}_{2 \text { peak }}}, \mathrm{W}_{\max }$ and $\mathrm{O}_{2}$ pulse in patients with COPD-PH were mainly driven by patients not candidates to lung transplant.

Our results showed that there is a reduced exercise tolerance due to the presence of $\mathrm{PH}$, although when we analysed the studies, including lung transplant candidates, these differences may not be so evident. Lung transplant candidates present worse lung function, and the presence of this great respiratory limitation may be difficult to distinguish from the influence of the cardiovascular limitation.

We analysed other exercise parameters. In the case of $V_{E}^{\prime}$, we found no differences when we considered the studies. However, if we excluded the studies on lung transplant candidates, we found a significant difference in ventilatory capacity. Although $\mathrm{FEV}_{1}$ did not show significant differences, there was a marked trend reduction on top of a significant reduction in $D_{\mathrm{LCO}}$ in the COPD-PH group that could explain this difference which directly influences ventilatory capacity and exercise tolerance. In the case of the $V^{\prime}{ }_{\mathrm{E}} / V^{\prime} \mathrm{CO}_{2}$ slope, there is probably a reporting bias because four out of the seven studies did not report it.

Due to the difficulty of analysing the $V_{\mathrm{E}}^{\prime} / V^{\prime} \mathrm{CO}_{2}$ slope to confirm whether the difference is ventilatory or cardiovascular, we analysed the ventilatory reserve. No significant difference in this parameter was found between the two groups; this shows that the cause of the dysfunction is cardiocirculatory and nonventilatory.

Regarding $\mathrm{FEV}_{1}$ between patients with COPD-PH and COPD-nonPH, although there was no significant difference in the meta-analysis $(\mathrm{p}=0.17)$, this result may be surprising and is probably mainly driven by the studies of SKJøERTEn et al. [28] and Blanco et al. [10]. This result may reflect that, in these studies, mainly patients with COPD with moderate $\mathrm{PH}$ with more severe airflow limitation were included and there were only a small number of patients with severe $\mathrm{PH}$. In fact, we consider that there are two patient profiles: on the one hand, there are patients with less severe airflow limitation where the presence of $\mathrm{PH}$ limits exercise tolerance, and on the other hand, patients with severe airflow obstruction (such as candidates to lung transplant) who show mild or severe $\mathrm{PH}$ and present exercise intolerance in which both airflow obstruction (ventilatory limitation) and $\mathrm{PH}$ (cardiovascular limitation) contribute to limiting their exercise capacity. In accordance with this, when analysing candidates for lung transplant, the differences are less apparent.

In summary, patients with COPD-PH have a lower level of exercise tolerance. The facts that support these findings are the lower $V^{\prime} \mathrm{O}_{2 \text { peak }}$ and $\mathrm{W}_{\text {max }}$ values, in line with a lower $\mathrm{O}_{2}$ pulse value. Unfortunately, it was not possible to check this outcome with the $V^{\prime}{ }^{\prime} / V^{\prime} \mathrm{CO}_{2}$ slope due to significant biases in its selection. Future studies should report this variable to confirm or rule out our finding.

\section{Applicability of the findings to the review question}

Our results show a reduction in exercise tolerance in patients with COPD-PH with important clinical implications. These results show the debilitating consequences of $\mathrm{PH}$ as a comorbidity; consequently, it is critical to detect the presence of $\mathrm{PH}$ in COPD patients. The clinical guidelines recommend that echocardiography should always be performed when $\mathrm{PH}$ is suspected. This noninvasive test appears to be a valid tool given its good correlation with the RHC and its possibility of being applied more widely and with fewer associated complications [35]. We think that routine evaluation of the presence of $\mathrm{PH}$ in patients with COPD is mandatory because it will allow for determining what kind of intervention to carry 
out, how beneficial it would be for patients and which patients would need stricter supervision, for example, if they do engage exercise or participate in rehabilitation programmes.

\section{Strengths}

Our systematic review has some strengths. We conducted a comprehensive search of the literature, including full-text publications, without language restrictions or the use of filters in the search strategy. Although we included studies published between 1950 and March 2020, it is unlikely that any may have been missed, given that the publications of well-designed and protocolised CPET began to appear in 1997 [36]. However, the guidelines that established the diagnosis criteria of PH are from 2004 [37]. The process of this systematic review was rigorous, and all the reviewing authors were appropriately trained and had experience in reviewing manuscripts.

\section{Limitations}

The most important limitation is the different designs of the selected studies (prospective, retrospective and cross-sectional). In particular, retrospective studies can affect the representativeness of the results since some key variables cannot be measured. Moreover, there may be a bias in patient selection. Another limitation is that not all the studies used the RHC as diagnostic criteria for $\mathrm{PH}$; only one of them used echocardiography for some of the patients [10]. Despite being a limitation, we intentionally accepted $\mathrm{PH}$ assessed by echocardiography because RHC is an invasive test not always recommended for routine assessment in patients with COPD, and considering that noninvasive measurement of PAP has shown a good correlation with RHC [38, 39]. Moreover, some of the studies included different severity levels of COPD and $\mathrm{PH}$, and some of the studies included lung transplant candidates. Although we examined by the severity of COPD, we were unable to analyse the differences in the variables studied between patients with severe $\mathrm{PH}$ and mild to moderate $\mathrm{PH}$. We think that future studies must consider the patient's disease severity to obtain more robust conclusions.

\section{Conclusion}

The $V_{\mathrm{O}_{2 \text { peak }}}^{\prime}, \mathrm{W}_{\max }$ and $\mathrm{O}_{2}$ pulse values were significantly lower in patients with COPD-PH than patients with COPD-nonPH, particularly in nontransplant candidates. Accordingly, the results of this systematic review reinforce the clinical value of CPET in routine evaluation of patients with COPD. Including CPET in a routine $\mathrm{PH}$ screening algorithm in patients with COPD could result in an earlier suspicious diagnosis.

Provenance: Submitted article, peer reviewed

Acknowledgments: Rodrigo Torres-Castro is a Ph.D. candidate in Methodology of Biomedical Research and Public Health Program, at Universitat Autònoma de Barcelona, Barcelona, Spain.

Clinical trial registration: The review was registered in PROSPERO (www.crd.york.ac.uk/prospero) with identifier CRD42019116660.

Authors contribution: R. Torres-Castro: conceptualisation, formal analysis, methodology, reviewing procedure and data extraction, writing (original draft, review and editing). E. Gimeno-Santos: conceptualisation, formal analysis, methodology, writing (original draft, review and editing). J. Vilaró: resolve disagreements between R. Torres-Castro and E. Gimeno-Santos, conceptualisation, writing (original draft, review and editing). M. Roqué-Figuls: formal analysis, methodology, writing (review and editing). J. Moisés: supervision, writing (review and editing). L. Vasconcello-Castillo: reviewing procedure and data extraction, writing (original draft, review and editing). T. Orizaga: supervision, writing (review and editing). J.A. Barberà: supervision, writing (review and editing). I. Blanco: conceptualisation, formal analysis, methodology, supervision, writing (original draft, review and editing).

Conflict of interest: None declared.

Support statement: The study was supported by grants from the Fondo de Investigación Sanitaria, Instituto de Salud Carlos III (PI17/1515), Fondo Europeo de Desarrollo Regional (FEDER), Unión Europea "Una manera de hacer Europa", Sociedad Española de Neumología y Cirugía Torácica (SEPAR) and Societat Catalana de Pneumologia (SOCAP). R. Torres-Castro is funded by a grant from the National Agency for Research and Development (ANID)/ Scholarship Program/DOCTORADO BECAS CHILE/2018-72190117. Funding information for this article has been deposited with the Crossref Funder Registry.

\section{References}

1 Singh D, Agusti A, Anzueto A, et al. Global strategy for the diagnosis, management, and prevention of chronic obstructive lung disease: the GOLD science committee report 2019. Eur Respir J 2019; 53: 1900164. 
2 Gredic M, Blanco I, Kovacs G, et al. Pulmonary hypertension in chronic obstructive pulmonary disease. $\mathrm{Br} \mathrm{J}$ Pharmacol 2021; 178: 132-151.

3 Wells JM, Washko GR, Han MLK, et al. Pulmonary arterial enlargement and acute exacerbations of COPD. N Engl J Med 2012; 367: 913-921.

4 Andersen $\mathrm{KH}$, Iversen M, Kjaergaard J, et al. Prevalence, predictors, and survival in pulmonary hypertension related to end-stage chronic obstructive pulmonary disease. J Hear Lung Transplant 2012; 31: 373-380.

5 Portillo K, Torralba Y, Blanco I, et al. Pulmonary hemodynamic profile in chronic obstructive pulmonary disease. Int J Chron Obstruct Pulmon Dis 2015; 10: 1313-1320.

6 Hilde JM, Skjørten I, Hansteen V, et al. Haemodynamic responses to exercise in patients with COPD. Eur Respir J 2013; 41: 1031-1041.

7 Blanco I, Piccari L, Barberà JA. Pulmonary vasculature in COPD: the silent component. Respirology 2016; 21 : 984-994.

8 Panagiotou M, Kastanakis E, Vogiatzis I. Exercise limitation in COPD. Pneumon 2013; 26: 245-256.

9 Cuttica MJ, Kalhan R, Shlobin OA, et al. Categorization and impact of pulmonary hypertension in patients with advanced COPD. Respir Med 2010; 104: 1877-1882.

10 Blanco I, Valeiro B, Torres-Castro R, et al. Effects of pulmonary hypertension on exercise capacity in patients with chronic obstructive pulmonary disease. Arch Bronconeumol 2020; 56: 499-505.

11 Thirapatarapong W, Armstrong HF, Bartels MN. Comparing cardiopulmonary exercise testing in severe COPD patients with and without pulmonary hypertension. Heart Lung Circ 2014; 23: 833-840.

12 Adir Y, Ollech JE, Vainshelboim B, et al. The effect of pulmonary hypertension on aerobic exercise capacity in lung transplant candidates with advanced emphysema. Lung 2015; 193: 223-229.

13 Pynnaert C, Lamotte M, Naeije R. Aerobic exercise capacity in COPD patients with and without pulmonary hypertension. Respir Med 2010; 104: 121-126.

14 Arena R, Sietsema KE. Cardiopulmonary exercise testing in the clinical evaluation of patients with heart and lung disease. Circulation 2011; 123: 668-680.

15 Herdy AH, Ritt LEF, Stein R, et al. Cardiopulmonary exercise test: background, applicability and interpretation. Arq Bras Cardiol 2016; 107: 467-481.

16 Kovacs G, Agusti A, Barberà JA, et al. Pulmonary vascular involvement in chronic obstructive pulmonary disease is there a pulmonary vascular phenotype? Am J Respir Crit Care Med 2018; 198: 1000-1011.

17 Nathan SD, Barbera JA, Gaine SP, et al. Pulmonary hypertension in chronic lung disease and hypoxia. Eur Respir J 2019; 53: 1801914.

18 Boerrigter BG, Bogaard HJ, Trip P, et al. Ventilatory and cardiocirculatory exercise profiles in COPD: the role of pulmonary hypertension. Chest 2012; 142: 1166-1174.

19 Cote CG, Pinto-Plata V, Kasprzyk K, et al. The 6-min walk distance, peak oxygen uptake, and mortality in COPD. Chest 2007; 132: 1778-1785.

20 Paolillo S, Agostoni P. Prognostic role of cardiopulmonary exercise testing in clinical practice. Ann Am Thorac Soc 2017; 14: S53-S58.

21 Holverda S, Bogaard HJ, Groepenhoff H, et al. Cardiopulmonary exercise test characteristics in patients with chronic obstructive pulmonary disease and associated pulmonary hypertension. Respiration 2008; 76: 160-167.

22 Moher D, Liberati A, Tetzlaff J, et al. Preferred reporting items for systematic reviews and meta-analyses: the PRISMA statement. Ann Intern Med 2009; 151: 264-269.

23 Stroup DF, Berlin JA, Morton SC, et al. Meta-analysis of observational studies in epidemiology: a proposal for reporting. J Am Med Assoc 2000; 283: 2008-2012.

24 Ouzzani M, Hammady H, Fedorowicz Z, et al. Rayyan - a web and mobile app for systematic reviews. Syst Rev 2016; 5: 210.

25 Hayden JA, van der Windt DA, Cartwright JL, et al. Assessing bias in studies of prognostic factors. Ann Intern Med 2013; 158: 280-286.

26 Riley RD, Moons KGM, Snell KIE, et al. A guide to systematic review and meta-analysis of prognostic factor studies. BMJ 2019; 364: k4597.

27 Higgins J, Thomas J, Chandler J, et al.. Cochrane Handbook for Systematic Reviews of Interventions Version 6.1 (updated September 2020). www.training.cochrane.org/handbook Date last accessed: 28 September 2020.

28 Skjørten I, Hilde JM, Melsom MN, et al. Cardiopulmonary exercise test and $\mathrm{PaO}_{2}$ in evaluation of pulmonary hypertension in COPD. Int J COPD 2018; 13: 91-100.

29 Xiong $\mathrm{W}, \mathrm{Xu} \mathrm{M}$, Pudasaini $\mathrm{B}$, et al. The influence of anemia on one-year exacerbation rate of patients with COPD-PH. BMC Pulm Med 2018; 18: 143.

30 Wu CW, Hsieh PC, Yang MC, et al. Impact of peak oxygen pulse on patients with chronic obstructive pulmonary disease. Int J COPD 2019; 14: 2543-2551.

31 Weatherald J, Farina S, Bruno N, et al. Cardiopulmonary exercise testing in pulmonary hypertension. Ann Am Thorac Soc 2017; 14: Suppl. 1, S84-S92. 
32 Corrà U, Giordano A, Mezzani A, et al. Cardiopulmonary exercise testing and prognosis in heart failure due to systolic left ventricular dysfunction: a validation study of the European Society of Cardiology Guidelines and Recommendations (2008) and further developments. Eur J Prev Cardiol 2012; 19: 32-40.

33 Groepenhoff $\mathrm{H}$, Vonk-Noordegraaf A, Boonstra A, et al. Exercise testing to estimate survival in pulmonary hypertension. Med Sci Sports Exerc 2008; 40: 1725-1732.

34 Sun XG, Hansen JE, Oudiz RJ, et al. Exercise pathophysiology in patients with primary pulmonary hypertension. Circulation 2001; 104: 429-435.

35 Galiè N, Humbert M, Vachiery JL, et al. 2015 ESC/ERS Guidelines for the diagnosis and treatment of pulmonary hypertension. Eur Respir J 2015; 46: 903-975.

36 Roca J, Whipp BJ, Agustí AGN, et al. Clinical exercise testing with reference to lung diseases: indications, standardization and interpretation strategies. Eur Respir J 1997; 10: 2662-2689.

37 McGoon M, Gutterman D, Steen V, et al. Screening, early detection, and diagnosis of pulmonary arterial hypertension: ACCP evidence-based clinical practice guidelines. Chest 2004; 126: Suppl. 1, 14S-34S.

38 Janda S, Shahidi N, Gin K, et al. Diagnostic accuracy of echocardiography for pulmonary hypertension: a systematic review and meta-analysis. Heart 2011; 97: 612-622.

39 Sato T, Tsujino I, Ohira H, et al. Validation study on the accuracy of echocardiographic measurements of right ventricular systolic function in pulmonary hypertension. J Am Soc Echocardiogr 2012; 25: 280-286. 